\title{
Development of feline embryos produced by Piezo-actuated intracytoplasmic sperm injection of elongated spermatids
}

\author{
Yasunori TSUJIMOTO ${ }^{1{ }^{*}}$, Kana FUJIKI ${ }^{1)^{*}}$, MD Emtiaj ALAM ${ }^{1)}$, Masaya TSUKAMOTO ${ }^{1)}$, \\ Rika AZUMA ${ }^{2)}$, Ryoji KANEGII), Masayuki ANZAI ${ }^{2,3)}$, Toshio INABA ${ }^{1)}$, Kikuya SUGIURA ${ }^{1)}$ and \\ Shingo HATOYA ${ }^{1)}$ \\ 1) Department of Advanced Pathobiology, Graduate School of Life and Environmental Sciences, Osaka Prefecture University, \\ Osaka 598-8531, Japan \\ ${ }^{2)}$ Division of Biological Science, Graduate School of Biology-Oriented Science and Technology, Kindai University, \\ Wakayama 649-6493, Japan \\ 3) Institute of Advanced Technology, Kindai University, Wakayama 642-0017, Japan
}

\begin{abstract}
Piezo-actuated intracytoplasmic sperm injection (Piezo-ICSI) is used as an efficient in vitro fertilization method with various animals. With this method, elongated spermatids are collected from testicular tissues and are easier to obtain from animals that unexpectedly die than ejaculate sperm. Additionally, elongated spermatid injection often results in the development of embryos and offspring. To develop assisted reproductive techniques (ARTs) for domestic cats, we examined the effects of oocyte activation on cleavage and embryo development after Piezo-ICSI with motile sperm (experiment 1) and after Piezo-ICSI with either testicular sperm or elongated spermatids (experiment 2). In experiment 1, the proportions of cleaved embryos, morulas, and blastocysts following Piezo-ICSI with ethanol activation were significantly higher $(\mathrm{P}<0.05)$ than in the non-activated groups. However, the proportion of blastocysts and the blastocyst quality did not differ significantly $(P>0.05)$ between the ethanol-activated and non-activated groups. In experiment 2 , the cleavage frequencies of oocytes after Piezo-ICSI of testicular sperm or elongated spermatids and ethanol activation were higher $(\mathrm{P}<0.05)$ than that of oocytes in the non-activated group, but the occurrence of blastocyst formation and quality of blastocysts did not differ between the activated and non-activated groups. In summary, cat embryos can be produced by Piezo-actuated microinjection of elongated spermatids. Ethanol activation increased the frequency of cleavage, but it affected neither the occurrence of blastocyst development nor the quality of blastocysts. These results represent an expansion in the repertoire of ARTs that are potentially applicable to both domestic and endangered species of cats.
\end{abstract}

Key words: Blastocyst, Elongated spermatid, Feline oocyte, Piezo-actuated intracytoplasmic sperm injection (Piezo-ICSI), Sperm

(J. Reprod. Dev. 65: 245-250, 2019)

$I_{\text {o }}^{\mathrm{n}}$ n recent years, some species of cats have been brought to the verge of extinction due to illegal hunting and the loss of habitats. In addition to habitat conservation and strategically managed breeding programs, another approach for maintaining biodiversity is to use assisted reproductive techniques (ARTs), such as gamete preservation and artificial insemination [1]. One impediment to efforts to improve breeding techniques of endangered cats is the limited access to gametes. During the past two decades, ARTs developed in domestic cats have been successfully applied to several species of non-domestic species [2]. While previous studies have shown the potential utility of ARTs for species conservation, these techniques have not been as

Received: September 30, 2018

Accepted: February 1, 2019

Published online in J-STAGE: February 18, 2019

C 2019 by the Society for Reproduction and Development

Correspondence: S Hatoya (e-mail: hatoya@vet.osakafu-u.ac.jp)

* Y Tsujimoto and K Fujiki contributed equally to this work.

This is an open-access article distributed under the terms of the Creative Commons Attribution Non-Commercial No Derivatives (by-nc-nd) License. (CC-BY-NC-ND 4.0: https://creativecommons.org/licenses/by-nc-nd/4.0/) broadly developed and applied with laboratory and livestock species for several reasons, including economic and political considerations, and (as mentioned above) limited gamete availability. Further studies to improve the efficacies of current techniques and to develop additional methods will assist in the propagation of endangered cats and cats that are biomedical models [2].

Piezo-actuated intracytoplasmic sperm injection (Piezo-ICSI) shows higher survival and fertilization rates than conventional ICSI in mice, humans, rats, cattle, and rabbits [3-8]. Because bovine oocytes contain an especially large number of lipid granules, structures inside the ooplasm (such as metaphase II chromosomes) are invisible under a light microscope. Thus, sperm injection by conventional methods can be more difficult than in species with oocytes that have a lighter, translucent ooplasm [6]. Piezo-ICSI disrupts the oolemma by Piezo electrical pulses and easily injects sperm into the oocytes. Thus, Piezo-ICSI is thought to be the most effective approach for fertilizing bovine oocytes [6]. Like bovine oocytes, cat oocytes have a dark/opaque ooplasm that prevents nuclear visualization under standard microscopy [9], but all previous reports on ICSI in cats have involved conventional methods [10-16]. Based on these 
observations, it is expected that the highest proportion of blastocysts could be obtained via Piezo-ICSI.

In some species, ICSI requires artificial oocyte activation. In cattle, fertilized eggs and offspring can be obtained by Piezo-ICSI, but embryo development is low when using non-activated oocytes [17]. However, when artificial oocyte activation treatment is applied, embryo development to the blastocyst stage is significantly improved, and calves can be obtained efficiently [7]. It has been reported that in cats, an artificial activation process is necessary to increase the incidence rate after conventional ICSI [10], but it is unknown whether artificial activation is necessary after Piezo-ICSI.

Ejaculated sperm collected by electrostimulation are normally used for ARTs in domestic and wild cats [18], but the use of these sperm is not applicable for endangered animals that could unexpectedly die. Therefore, spermatids in testes from animals that unexpectedly die can be meaningfully used to produce embryos by microinjection. In domestic cats, blastocysts have been successfully produced using testicular spermatozoa $[11,14,19]$. However, no reports have described embryo production via ICSI of elongated spermatids. If blastocysts are produced using elongated spermatids, then male gametes other than sperm can be secured and more fertilized oocytes can be produced. Based on these collective observations, we performed two experiments in this study, namely we examined the effect of ethanol-induced oocyte activation on cleavage and embryo development after Piezo-ICSI with epididymal sperm (experiment 1), or after Piezo-ICSI with either testicular sperm or elongated spermatids (experiment 2).

\section{Material and Methods}

In this study, cat ovaries and testes with epididymides were collected from a local veterinary clinic following a routine ovariohysterectomy and castration. The animals were neither operated on, nor sacrificed for this study. The uses of tissues were approved by the ethics committee of a local veterinary clinic. All cats were privately owned and the owners provided consent before the samples were collected.

\section{Collection of oocytes and in vitro maturation}

We collected ovaries from domestic short-haired cats that underwent an ovariohysterectomy at a local veterinary clinic. The ovaries were maintained in $0.8 \%(\mathrm{w} / \mathrm{v})$ saline solution and transported to our laboratory within $6 \mathrm{~h}$ at room temperature. Oocyte collection and in vitro maturation (IVM) were conducted as previously described [20]. Briefly, cumulus-oocyte complexes (COCs) were collected after cutting ovaries in Medium 199 (Thermo Fisher Scientific, Waltham, MA, USA). We used oocytes that were completely surrounded with over four layers of compacted cumulus cells. The COCs were collected and rinsed three times in IVM medium, which comprised Medium 199 medium supplemented with $0.4 \%(\mathrm{w} / \mathrm{v})$ bovine serum albumin (BSA; Sigma-Aldrich, St. Louis, MO, USA), 10 IU/ml 17 $\beta$-estradiol (Sigma-Aldrich), $100 \mu \mathrm{g} / \mathrm{ml}$ gentamycin (Sigma-Aldrich), $137 \mu \mathrm{g} /$ $\mathrm{ml}$ sodium pyruvate (Sigma-Aldrich), $0.02 \mathrm{IU} / \mathrm{ml}$ Follistim ${ }^{\circledR}$ (human recombinant follicle-stimulating hormone; MSD, Tokyo, Japan), and $25 \mathrm{ng} / \mathrm{ml}$ epidermal growth factor (Sigma-Aldrich). Then, the COCs were incubated for $28 \mathrm{~h}$ in $100 \mu \mathrm{IVM}$ medium droplets covered with mineral oil (Sigma-Aldrich) in an incubator at $38.5^{\circ} \mathrm{C}$ with $5 \% \mathrm{CO}_{2}$.
Sperm collection and cryopreservation

Testes were obtained from a local veterinary clinic. After removing external tissues from testes, we then separated the epididymides. The epididymides were cut into small pieces in Dulbecco's phosphatebuffered saline without $\mathrm{Ca}^{2+}$ and $\mathrm{Mg}^{2+}$ (PBS (-), Nacalai, Kyoto, Japan) and cultured at $38.5^{\circ} \mathrm{C}$ under $5 \% \mathrm{CO}_{2}$ in humidified air for $10 \mathrm{~min}$. After filtering through a $20-\mu \mathrm{m}$ filter (Nipro, Osaka, Japan), the semen was centrifuged for $5 \mathrm{~min}$ at $500 \times g$, and the seminal plasma was removed by aspirating the supernatant. The pelleted sperm were resuspended in m-HTF medium (Nippon Medical \& Chemical Instruments, Osaka, Japan) to prepare a sperm suspension.

The sperm suspension was mixed with EYT-FC solution, which comprised egg yolk supplemented with $13 \mu \mathrm{g} / \mathrm{ml}$ citric acid (Nacalai), $10 \mu \mathrm{g} / \mathrm{ml}$ D-fructose (Nacalai), $24 \mu \mathrm{g} / \mathrm{ml}$ Tris aminomethane (Nacalai), $1000 \mathrm{IU} / \mathrm{ml}$ Penicillin (Sigma-Aldrich), and $1 \mathrm{mg} / \mathrm{ml}$ streptomycin (Sigma-Aldrich), and stored at $4^{\circ} \mathrm{C}$. After $1 \mathrm{~h}$, EYT-FC solution containing $14 \%(\mathrm{v} / \mathrm{v})$ glycerol (Nacalai) was added the solution to obtain a final concentration of $12.5 \times 10^{6}$ cells $/ \mathrm{ml}$, with a final glycerol concentration of $7 \%$. Then, this solution was loaded into 0.25-ml straws (Fujihira, Tokyo, Japan). After sealing, the straws were laid horizontally on a rack $4 \mathrm{~cm}$ above liquid nitrogen vapor for 5 min, plunged into liquid nitrogen, and stored in a liquid nitrogen storage tank.

\section{Thawing of cryopreserved sperm}

Straws containing cryopreserved sperm were thawed by soaking in $37^{\circ} \mathrm{C}$ water for $30 \mathrm{sec}$. The sperm were then released into $\mathrm{m}-\mathrm{HTF}$ medium. This solution was centrifuged for $5 \mathrm{~min}$ at $500 \times \mathrm{g}$, and resulting sperm were resuspended in HTF medium (Nippon Medical $\&$ Chemical Instruments). The resuspended sperm were centrifuged for $5 \mathrm{~min}$ at $500 \times \mathrm{g}$, and the resulting sperm were added to $\mathrm{m}$-HTF medium.

\section{Testicular sperm and extraction of elongated spermatids}

After the removal of tunica, seminiferous tubules were placed in $\mathrm{m}$-HTF medium and cut into small pieces with a pair of fine scissors. After using the same protocol followed for sperm collection, the final suspension contained testicular sperm and spermatogenic cells in various developmental stages.

Piezo-ICSI of epididymal sperm, testicular sperm, and elongated spermatids

Piezo was performed using an IX71 inverted microscope (Olympus, Tokyo, Japan) equipped with a Piezo micromanipulator (MB-U, Prime Tech, Ibaraki, Japan). Injection pipettes had a deflection angle of $28^{\circ}$ and a $6-\mu \mathrm{m}$ outer diameter. Holding pipettes had a 10 to $15 \mu \mathrm{m}$ inner diameter and a 100- $\mu \mathrm{m}$ outer diameter, with a fire-polished tip. The COCs incubated in IVM medium were pipetted gently many times to remove the cumulus layers. Denuded oocytes showing a first polar body under a stereomicroscope were regarded as being in metaphase II (M II) and were only used for microinjection. Two droplets of frozen sperm-12\% polyvinylpyrrolidone (molecular weight: 36,000 , Kanto Kagaku, Tokyo, Japan) in m-HTF suspension and six $5-\mu 1$ droplets of $m$-HTF containing the denuded oocytes were placed in the chamber under mineral oil. The chamber comprised a 40-mm $\times 50-\mathrm{mm}$ cover glass (Matsunami Glass, Osaka, Japan) 
bonded to a 50-mm $\times 50-\mathrm{mm}$ slide glass (Matsunami Glass) with a 30-mm diameter hole in the center. Morphologically normal and progressively motile epididymal sperm were used. The M II oocytes were held to the holding pipette with the polar body at the 12 or 6 o'clock position and the injection pipette at the 3 o'clock position to avoid damaging the oocytes. The zona pellucida of each oocyte was drilled by applying several Piezo pulses to the sperm-injection pipette. After the sperm was pushed forward (until its head was near the tip of injection pipette), the pipette was advanced until its tip almost reached the opposite side of the oocyte cortex. The oolemma was broken by applying a single Piezo pulse, and the entire sperm was expelled into the ooplasm before the pipette was gently withdrawn. All procedures were performed at room temperature. Injected oocytes were maintained at room temperature for approximately $10 \mathrm{~min}$.

Morphologically normal and immotile testicular sperm, as well as morphologically normal elongated spermatids (Fig. 1) were injected into oocytes as described above.

\section{Activation}

After microinjection, oocytes were blindly divided into two groups. Oocyte activation was conducted as described [10]. One group was treated for $10 \mathrm{~min}$ at $38.5^{\circ} \mathrm{C}$ under $5 \% \mathrm{O}_{2}$ with $\mathrm{HTF}$ medium containing $7 \%(\mathrm{v} / \mathrm{v})$ ethanol. The other group was not treated.

\section{Embryo culture}

After microinjection and activation, oocytes were cultured in Only-One medium (Nippon Medical \& Chemical Instruments) supplemented with $0.3 \%(\mathrm{w} / \mathrm{v})$ BSA for 2 days at $38.5^{\circ} \mathrm{C}$ with $5 \%$ $\mathrm{O}_{2}, 5 \% \mathrm{CO}_{2}$, and $90 \% \mathrm{~N}_{2}$. Subsequently, cleaved embryos were washed and cultured for 5 days in Only-one medium containing 5\% (w/v) fetal bovine serum (Biosolutions International, Melbourne, Australia) at $38.5^{\circ} \mathrm{C}$ with $5 \% \mathrm{O}_{2}, 5 \% \mathrm{CO}_{2}$, and $90 \% \mathrm{~N}_{2}$. The percentages of cleaved embryos, morulas, and blastocysts (related to the number of injected oocytes) were determined on days 2, 5, and 7 after microinjection. All blastocysts were rinsed twice with PBS (-). Then, the blastocysts were fixed and stained in $100 \%$ ethanol including $25 \mu \mathrm{g} / \mathrm{ml}$ bisbenzimide (Hoechst 33342, Sigma-Aldrich) for 2 to 3 $\mathrm{h}$ at $4^{\circ} \mathrm{C}$. Stained blastocysts were examined under a fluorescence microscope to determine the numbers of cells.

\section{Statistical analyses}

All experiments were repeated independently at least 4 times. Results are expressed as the mean \pm the standard error of the mean (SEM). Statistical differences were evaluated by analysis of variance and the Tukey-Kramer method (Statcel 3; OMC Publishing, Saitama, Japan). In all cases, differences were considered significant when $\mathrm{P}<0.05$.

\section{Experiment design}

Experiment 1: in vitro embryo development after Piezo-ICSI

In experiment 1 , morphologically normal and progressively motile sperm were used. A total of $334 \mathrm{M}$ II oocytes was divided among three groups: 1 ) activated oocytes $(\mathrm{N}=140), 2)$ non-activated oocytes $(\mathrm{N}=124)$, and 3) sham-treated oocytes (injection without sperm, $\mathrm{N}$ $=70)$ to serve as the control. The developmental competence of the microinjected oocytes was assessed in terms of cleavage, morula

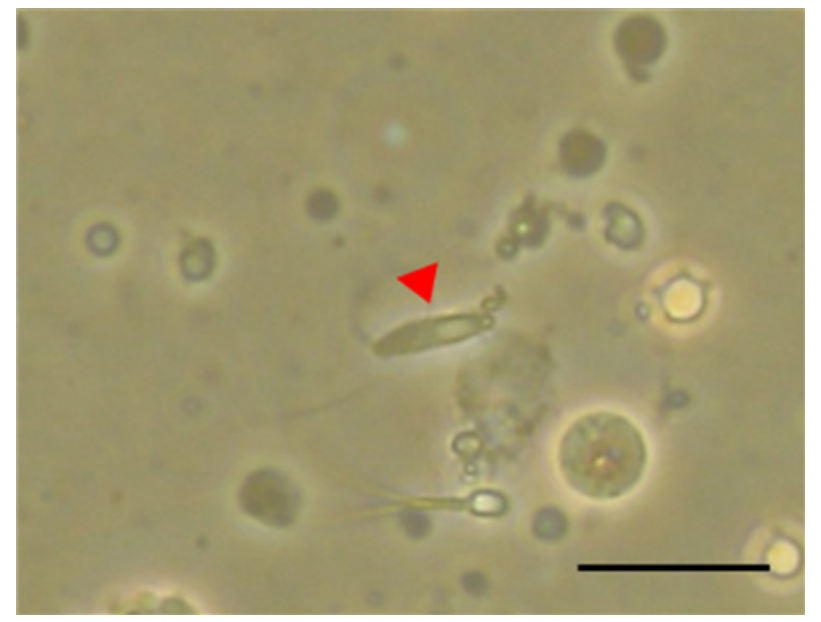

Fig. 1. An elongated spermatid shown with an elongating tail from the centrioles of the cell (arrow: magnification, $\times 400$ ). The tail of the sperm is elongating from the centrioles of the cell. The scale bar represents $20 \mu \mathrm{m}$.

and blastocyst formation percentages on days 2, 5, and 7 of in vitro culture (day $0=\mathrm{ICSI}$ ), respectively. Only embryos with $\geq 32$ cells and a visible blastocoel cavity were classified as blastocysts.

Experiment 2: in vitro embryo development after Piezo-ICSI with testicular sperm and elongated spermatids

In experiment 2, morphologically normal and progressively motile sperm, morphologically normal and immotile testicular sperm, and morphologically normal elongated spermatids were used. A total of $635 \mathrm{M}$ II oocytes was divided among the five treatment groups, as follows: 1) Piezo-ICSI with testicular sperm, plus ethanol activation $(\mathrm{N}=113), 2)$ Piezo-ICSI with testicular sperm, no ethanol activation ( $\mathrm{N}=123)$, 3) Piezo-ICSI with elongated spermatids, plus ethanol activation ( $\mathrm{N}=123)$, 4) Piezo-ICSI of elongated spermatids, no ethanol activation $(\mathrm{N}=122)$, and 5) Piezo-ICSI of epididymal sperm without ethanol activation $(\mathrm{N}=154)$ to serve as the control. Cleavage and embryo development were evaluated as described above.

\section{Results}

\section{In vitro embryo development after Piezo-ICSI}

As shown in Table 1, in experiment 1, the proportions of cleaved embryos, and morulas after Piezo-ICSI with ethanol activation were significantly higher $(\mathrm{P}<0.05)$ than in the non-activated groups. However, the proportions of blastocysts in the ethanol-activated and non-activated groups were similar $(\mathrm{P}>0.05)$. In addition, the blastocyst quality in terms of the average number of cells did not significantly differ $(\mathrm{P}>0.05)$ between blastocysts in the ethanolactivated and non-activated groups. No blastocyst development was observed in the sham group.

In vitro embryo development after Piezo-ICSI with testicular sperm and elongated spermatids

As shown in Table 2, in experiment 2, the percent cleavages of testicular spermatozoa in the activated group and the elongated 
Table 1. Developmental competence of cat embryos after Piezo-ICSI using epididymal sperm (experiment 1)

\begin{tabular}{lccccc}
\hline \multirow{2}{*}{ Treatment } & \multirow{2}{*}{ Number of oocytes } & \multicolumn{3}{c}{ Stage of development (\%) } & \multirow{2}{*}{ Blast cells, N } \\
\cline { 3 - 5 } & & Cleavage & Morula & Blastocyst & \\
\hline Activation & 140 & $81.4 \pm 3.8^{\mathrm{a}}$ & $30.3 \pm 4.3^{\mathrm{a}}$ & $9.1 \pm 2.8^{\mathrm{a}}$ & $144.8 \pm 36.1$ \\
No activation & 124 & $50.4 \pm 5.6^{\mathrm{b}}$ & $16.1 \pm 3.6^{\mathrm{b}}$ & $9.2 \pm 2.6^{\mathrm{a}}$ & $116.0 \pm 12.1$ \\
Sham & 70 & $14.4^{\mathrm{a}} \pm 2.5^{\mathrm{c}}$ & $2.4 \pm 2.4^{\mathrm{c}}$ & $0^{\mathrm{b}}$ & N.D. \\
\hline
\end{tabular}

Data are expressed as the mean \pm the standard error of the mean (SEM). Different superscripted letters indicate significant differences $(\mathrm{P}<0.05)$. N.D. means not determined.

Table 2. Developmental competence of cat embryos after Piezo-ICSI using testicular sperm and elongated spermatids (experiment 2)

\begin{tabular}{|c|c|c|c|c|c|c|}
\hline \multirow{2}{*}{\multicolumn{2}{|c|}{ Treatment }} & \multirow{3}{*}{$\begin{array}{c}\text { Number of oocytes } \\
113\end{array}$} & \multicolumn{3}{|c|}{ Stage of development (\%) } & \multirow{3}{*}{$\begin{array}{r}\text { Blast cells, N } \\
132.8 \pm 8.7\end{array}$} \\
\hline & & & \multirow{2}{*}{$\frac{\text { Cleavage }}{77.8 \pm 3.2^{\mathrm{a}}}$} & \multirow{2}{*}{$\frac{\text { Morula }}{20.5 \pm 2.3^{a, b}}$} & \multirow{2}{*}{$\begin{array}{l}\text { Blastocyst } \\
11.3 \pm 4.3\end{array}$} & \\
\hline Testicular sperm & Activation & & & & & \\
\hline & No activation & 123 & $50.2 \pm 4.1^{b}$ & $10.0 \pm 2.1^{\mathrm{b}}$ & $7.6 \pm 2.0$ & $151.8 \pm 26.3$ \\
\hline \multirow[t]{2}{*}{ Elongated spermatid } & Activation & 123 & $71.8 \pm 3.7^{\mathrm{a}}$ & $22.2 \pm 2.7^{\mathrm{a}}$ & $4.1 \pm 2.5$ & $151.0 \pm 33.2$ \\
\hline & No activation & 122 & $43.7 \pm 5.5^{b}$ & $9.0 \pm 4.2^{b}$ & $4.4 \pm 1.4$ & $117.8 \pm 13.8$ \\
\hline Sperm & & 154 & $50.5 \pm 6.7^{b}$ & $14.0 \pm 2.9^{\mathrm{a}, \mathrm{b}}$ & $12.2 \pm 2.8$ & $151.8 \pm 20.8$ \\
\hline
\end{tabular}

Date are expressed as the mean \pm the SEM. Different superscripted letters indicate significant differences $(\mathrm{P}<0.05)$.
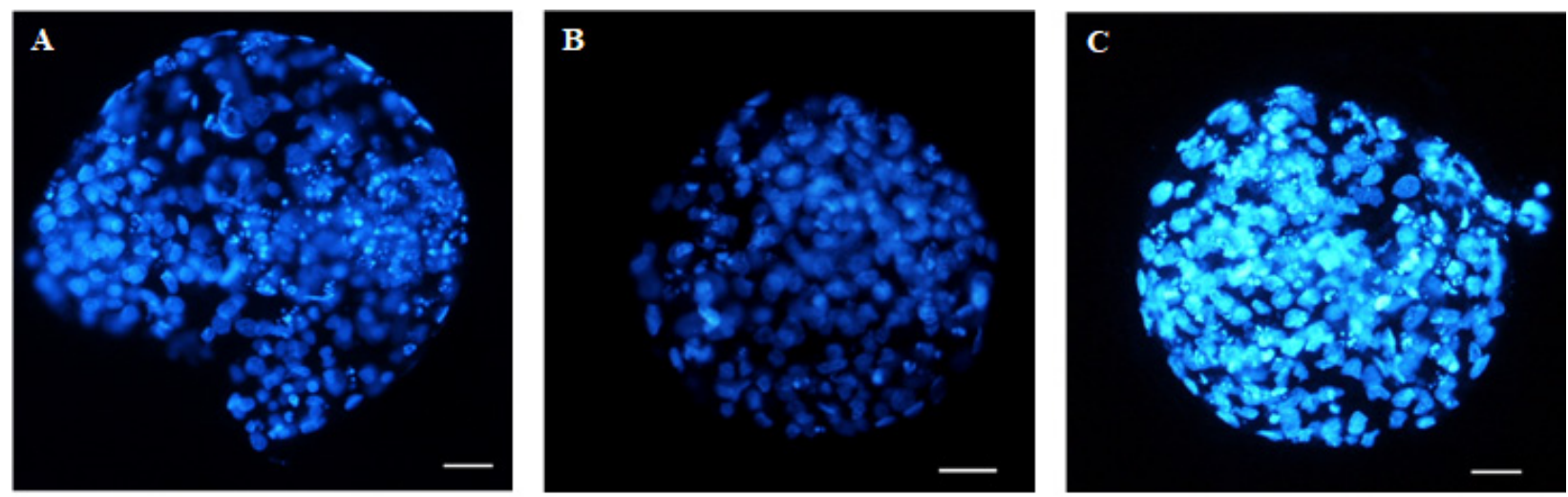

Fig. 2. Cat blastocysts stained with bis-benzimide (Hoechst 33342) were visualized under a fluorescence microscope (magnification, $\times 200)$. (A) Blastocyst derived from Piezo-ICSI with a sperm cell. (B) Blastocyst derived from Piezo-ICSI with a testicular sperm. (C) Blastocyst derived from Piezo-ICSI with an elongated spermatid. The scale bar represents $30 \mu \mathrm{m}$.

spermatids in the activated group were significantly higher $(\mathrm{P}<0.05)$ than those in the non-activated groups. The proportion of morulas in elongated spermatids in the activated group was significantly higher $(\mathrm{P}<0.05)$ than that of testicular sperm and elongated spermatids in the non-activated group. The blastocyst-formation rates were not different in any of the groups. Blastocysts generated with sperm and blastocysts generated with elongated spermatids were not morphologically different. In addition, the blastocyst quality as measured by the number of cells in each blastocyst were not different in any of the groups (Figs. 2A-C).

\section{Discussion}

In experiment 1 , the percentages of cleaved embryos, morulas and blastocysts significantly increased in the Piezo-ICSI group as compared with the sham group. Because oocytes in the sham group did not develop into blastocysts, we succeeded in obtaining blastocysts without parthenogenesis by Piezo-ICSI. In addition, over $9 \%$ of $\mathrm{M}$ II oocytes developed into blastocysts after Piezo-ICSI, which is substantially higher than that reported by Bogliolo et al. [10], who showed that conventional ICSI yielded blastocysts at a proportion of $5.4 \%$. Thus, Piezo-ICSI does not cause damages due to oocyte deformation, increased internal pressure, or ooplasm suction, which do occur with conventional ICSI [4]. Therefore, Piezo-ICSI appeared 
to be very useful for fertilizing feline oocytes.

In experiment 2, blastocysts were produced by Piezo-ICSI with testicular sperm. A previous report showed that the percentage of cleavage was $39.7 \%$ and that the proportion of blastocysts was $5.5 \%$ [11], using conventional ICSI. In contrast, the percentage of cleavage was $50.1 \%$ and the proportion of blastocysts was $7.6 \%$ in experiment 2 . In addition, we succeeded in producing blastocysts with elongated spermatids for the first time in cats. These results can be explained by considering that Piezo-ICSI can activate oocytes [4] and that conventional ICSI may cause more damage to oocytes than Piezo-ICSI by penetrating the zona pellucida and the oocyte membranes with a sharpened needle at the tip [3].

In this study, we found that the blastocyst-formation rate and cell numbers were not different when using elongated spermatids or sperm. A frequently used measure of blastocyst quality is to count the number of cells visible by fluorescence [14]. Here, we demonstrated that blastocysts produced by Piezo-ICSI with elongated spermatids had the same number of cells as those of blastocysts derived from sperm. In rabbits, blastocyst formation rate and number of cells/ blastocyst from oocytes injected with elongated spermatids were lower than those of oocytes injected with sperm [21]. In this study, we demonstrated the feasibility and potential utility of producing cat embryos by Piezo-ICSI of elongated spermatids. Furthermore, it has been reported that elongated spermatids from humans and members of the Mastomys genus can be frozen [22, 23]. Thus, cryopreservation of elongated spermatids can potentially enable the preservation of genetic material of feline species. In addition, in the common marmoset, elongated spermatids could be collected from immature male tests [24]. In cats, it is also possible to collect elongated spermatids from immature individuals. If elongated spermatids from immature male cat can be used for Piezo-ICSI, then more male gametes can be secured and more fertilized oocytes can be produced.

In both experiments 1 and 2 , the percent cleavage of all activated groups was significantly higher than that of the non-activated groups. The proportion of morulas in elongated spermatids in the activated group was significantly higher than that of testicular sperm and elongated spermatids in the non-activated group. In contrast, the incidences of blastocyst formation in the activated groups were not significantly different from that in the non-activated group. During fertilization, oocyte activation with $\mathrm{Ca}^{2+}$ oscillation is needed to resume oocyte meiosis [25]. In a previous study, pronuclear formation in sperm-injected bovine oocytes and subsequent blastocyst development were inhibited because the maturation-promoting factor (MPF) activity of oocytes was temporarily elevated at $4 \mathrm{~h}$ after microinjection [26]. The MPF activity decreased and the incidence of blastocyst development was increased by artificial activation at 4 $\mathrm{h}$ after microinjection [26, 27]. However, in rabbits, the incidence of blastocyst formation was increased by oocyte-activation treatment before microinjection [28]. Therefore, the optimal time for artificial activation of oocytes may be species-specific. In these experiments, with reference to a previous report [10], the activation treatment was performed immediately after microinjection; however, it is possible that the optimal timing for the activation treatment depends on multiple variables. It was reported that treatment with ethanol activated $74.2 \%$ of bovine oocytes, whereas cat oocytes were only activated at a rate of $34.1 \%$ [29]. Ethanol activates oocytes by causing a transient increase in the intracellular $\mathrm{Ca}^{2+}$ concentration [30]. The results of several reports show that $\mathrm{Ca}^{2+}$ oscillations led to normal embryonic development and an increased frequency of blastocyst formation [31-33].

In addition, elongated spermatids of several species can cause oocyte activation, but their activation abilities show species-specific differences. In rabbits, over $75 \%$ of oocytes injected with elongated spermatids were activated and $\mathrm{Ca}^{2+}$ oscillations were induced [34]. For this reason, artificial activation has not been carried out by microinjection using elongated spermatids in rabbits [21,35]. Although $89 \%$ of oocytes injected with elongated spermatids were activated in mice, $\mathrm{Ca}^{2+}$ oscillations were not observed and only a few $\mathrm{Ca}^{2+}$ rises observed [34]. However, mouse oocytes injected with elongated spermatids can develop into offspring at high rate without artificial stimulation of oocytes [36]. Therefore, a few $\mathrm{Ca}^{2+}$ rises were sufficient for mouse oocyte activation [36]. In rats, only $39 \%$ of oocytes were activated after microinjection with elongated spermatids, and artificial activation was necessary for embryogenesis [34]. In cats, a comparison of the oocyte-activation ability of testicular sperm with that of elongated spermatids has not been reported. In this study, cleavage was observed, but many embryos did not develop into blastocysts. Activation methods include strontium, ionomycin, electric stimulation, and other methods besides ethanol. Few reports have described the use of artificial stimulation for ICSI in cats. In this study, we used the ethanol activation because a previous report described it use for conventional ICSI in cats [10]. Consequently, ethanol activation may be insufficient as an activation treatment for cat oocytes. In the future, it will be necessary to investigate the timing of the activation treatment for Piezo-ICSI in cats and to perform multiple stimulations with electrical pulses, or to test several reagents (alone or in combination) to artificially induce $\mathrm{Ca}^{2+}$ oscillations as an activation method.

In summary, we produced cat blastocysts by Piezo-ICSI with greater efficiency than reported previously by conventional microinjection of testicular sperm. In addition, we succeeded in obtaining blastocysts using elongated spermatids for the first time. The techniques described in our report represent an expansion in the availability of assisted reproductive technologies that have potential application to enhancing propagation of both domestic and endangered cats.

\section{Acknowledgements}

We wish to thank Dr Masataka Nakaya (Department of Stem Cells and Human Disease Models, Research Center for Animal Life Science, Shiga University of Medical Science) for providing advice on the experimental methods.

This study was supported by Grant-in-Aid for Young Scientists (B) No. 24780311, and Grant-in-Aid for Science Research (C) No. $15 \mathrm{~K} 07747$ and (B) No. $18 \mathrm{H} 02349$ from the Japan Society for the Promotion of Science.

\section{References}

1. Silver LM. New reproductive technologies in the treatment of human infertility and genetic disease. Theor Med 1990; 11: 103-110. [Medline] [CrossRef]

2. Pope CE. Embryo technology in conservation efforts for endangered felids. Theriogenology 2000; 53: 163-174. [Medline] [CrossRef] 
3. Kimura Y, Yanagimachi R. Intracytoplasmic sperm injection in the mouse. Biol Reprod 1995; 52: 709-720. [Medline] [CrossRef]

4. Yanagida K, Katayose H, Yazawa H, Kimura Y, Konnai K, Sato A. The usefulness of a piezo-micromanipulator in intracytoplasmic sperm injection in humans. Hum Reprod 1999; 14: 448-453. [Medline] [CrossRef]

5. Dozortsev D, Wakaiama T, Ermilov A, Yanagimachi R. Intracytoplasmic sperm injection in the rat. Zygote 1998; 6: 143-147. [Medline] [CrossRef]

6. Katayose H, Yanagida K, Shinoki T, Kawahara T, Horiuchi T, Sato A. Efficient injection of bull spermatozoa into oocytes using a Piezo-driven pipette. Theriogenology 1999; 52: 1215-1224. [Medline] [CrossRef]

7. Horiuch T, Emuta C, Yamauchi Y, Oikawa T, Numabe T, Yanagimachi R. Birth of normal calves after intracytoplasmic sperm injection of bovine oocytes: a methodological approach. Theriogenology 2002; 57: 1013-1024. [Medline] [CrossRef]

8. Suzuki C, Hosoi Y, Kato H, Matsumoto K, Saeki K, Iritani A. Efficiency of rabbit Piezo-ICSI compared to conventional ICSI. Mem Research Inst BOST Kinki University. 2000: 30-33 (in Japanese).

9. Apparicio M, Ferreira CR, Tata A, Santos VG, Alves AE, Mostachio GQ, PiresButler EA, Motheo TF, Padilha LC, Pilau EJ, Gozzo FC, Eberlin MN, Lo Turco EG, Luvoni GC, Vicente WR. Chemical composition of lipids present in cat and dog oocyte by matrix-assisted desorption ionization mass spectrometry (MALDI- MS). Reprod Domest Anim 2012; 47(Suppl 6): 113-117. [Medline] [CrossRef]

10. Bogliolo L, Leoni G, Ledda S, Naitana S, Zedda M, Carluccio A, Pau S. Intracytoplasmic sperm injection of in vitro matured oocytes of domestic cats with frozen-thawed epididymal spermatozoa. Theriogenology 2001; 56: 955-967. [Medline] [CrossRef]

11. Buarpung S, Tharasanit T, Comizzoli P, Techakumphu M. Feline spermatozoa from fresh and cryopreserved testicular tissues have comparable ability to fertilize matured oocytes and sustain the embryo development after intracytoplasmic sperm injection. Theriogenology 2013; 79: 149-158. [Medline] [CrossRef]

12. Buarpung S, Tharasanit T, Comizzoli P, Techakumphu M. Effects of cold storage on plasma membrane, DNA integrity and fertilizing ability of feline testicular spermatozoa. Anim Reprod Sci 2012; 131: 219-227. [Medline] [CrossRef]

13. Comizzoli P, Wildt DE, Pukazhenthi BS. Poor centrosomal function of cat testicular spermatozoa impairs embryo development in vitro after intracytoplasmic sperm injection. Biol Reprod 2006; 75: 252-260. [Medline] [CrossRef]

14. Comizzoli P, Wildt DE, Pukazhenthi BS. In vitro development of domestic cat embryos following intra-cytoplasmic sperm injection with testicular spermatozoa. Theriogenology 2006; 66: 1659-1663. [Medline] [CrossRef]

15. Gómez MC, Pope CE, Harris R, Davis A, Mikota S, Dresser BL. Births of kittens produced by intracytoplasmic sperm injection of domestic cat oocytes matured in vitro. Reprod Fertil Dev 2000; 12: 423-433. [Medline] [CrossRef]

16. Pope CE, Johnson CA, McRae MA, Keller GL, Dresser BL. Development of embryos produced by intracytoplasmic sperm injection of cat oocytes. Anim Reprod Sci 1998; 53: 221-236. [Medline] [CrossRef]

17. Wei H, Fukui Y. Births of calves derived from embryos produced by intracytoplasmic sperm injection without exogenous oocyte activation. Zygote 2002; 10: 149-153. [Medline] [CrossRef]

18. Zambelli D, Cunto M. Semen collection in cats: techniques and analysis. Theriogenology 2006; 66: 159-165. [Medline] [CrossRef]

19. Buarpung S, Tharasanit T, Thongkittidilok C, Comizzoli P, Techakumphu M. Spermatozoa isolated from cat testes retain their structural integrity as well as a developmental potential after refrigeration for up to 7 days. Zygote 2015; 23: 644-651. [Medline] [CrossRef]

20. Kanegi R, Hatoya S, Tsujimoto Y, Takenaka S, Nishimura T, Wijewardana V, Sugiura K, Takahashi M, Kawate N, Tamada H, Inaba T. Production of feline leukemia inhibitory factor with biological activity in Escherichia coli. Theriogenology 2016; 86: 604-611.
[Medline] [CrossRef]

21. Ogonuki N, Inoue K, Miki H, Mochida K, Hatori M, Okada H, Takeiri S, Shimozawa N, Nagashima H, Sankai T, Ogura A. Differential development of rabbit embryos following microinsemination with sperm and spermatids. Mol Reprod Dev 2005; 72 411-417. [Medline] [CrossRef]

22. Al-Hasani S, Ludwig M, Palermo I, Küpker W, Sandmann J, Johannisson R, Fornara P, Sturm R, Bals-Pratsch M, Bauer O, Diedrich K. Intracytoplasmic injection of round and elongated spermatids from azoospermic patients: results and review. Hum Reprod 1999; 14(Suppl 1): 97-107. [Medline] [CrossRef]

23. Ogonuki N, Mochida K, Inoue K, Matsuda J, Yamamoto Y, Takano K, Ogura A. Fertilization of oocytes and birth of normal pups following intracytoplasmic injection with spermatids in mastomys (Praomys coucha). Biol Reprod 2003; 68: 1821-1827. [Medline] [CrossRef]

24. Ogonuki N, Inoue H, Matoba S, Kurotaki YK, Kassai H, Abe Y, Sasaki E, Aiba A, Ogura A. Oocyte-activating capacity of fresh and frozen-thawed spermatids in the common marmoset (Callithrix jacchus). Mol Reprod Dev 2018; 85: 376-386. [Medline] [CrossRef]

25. Miyazaki S, Igusa Y. Fertilization potential in golden hamster eggs consists of recurring hyperpolarizations. Nature 1981; 290: 702-704. [Medline] [CrossRef]

26. Fujinami N, Hosoi Y, Kato H, Matsumoto K, Saeki K, Iritani A. Activation with ethanol improves embryo development of ICSI-derived oocytes by regulation of kinetics of MPF activity. J Reprod Dev 2004; 50: 171-178. [Medline] [CrossRef]

27. Horiuchi T, Numabe T. Intracytoplasmic sperm injection (ICSI) in cattle and other domestic animals: problems and improvements in practical use. J Mamm Ova Res 1999 16: 1-9. [CrossRef]

28. Zhou X, Yin M, Jiang W, Jiang M, Li S, Li H, Chen X. Electrical activation of rabbit oocytes increases fertilization and embryo development by intracytoplasmic sperm injection using sperm from deceased male. J Assist Reprod Genet 2013; 30: 1605-1610. [Medline] [CrossRef]

29. Tanihara F, Kaedei Y, Namula Z, Luu VV, Sato Y, Wittayarat M, Taniguchi M, Oto T. Comparison of activation ability between feline and bovine oocytes. Acta Vet Hung 2013; 61: 491-494. [Medline] [CrossRef]

30. Deng MQ, Fan BQ. Intracellular $\mathrm{Ca}^{2+}$ during fertilization and artificial activation in mouse oocytes. Zhongguo Yao Li Xue Bao 1996; 17: 357-360. [Medline]

31. Grupen CG, Verma PJ, Du ZT, McIlfatrick SM, Ashman RJ, Nottle MB. Activation of in vivo- and in vitro-derived porcine oocytes by using multiple electrical pulses. Reprod Fertil Dev 1999; 11: 457-462. [Medline] [CrossRef]

32. Escribá MJ, García-Ximénez F. Influence of sequence duration and number of electrical pulses upon rabbit oocyte activation and parthenogenetic in vitro development. Anim Reprod Sci 2000; 59: 99-107. [Medline] [CrossRef]

33. Knott JG, Kurokawa M, Fissore RA, Schultz RM, Williams CJ. Transgenic RNA interference reveals role for mouse sperm phospholipase Czeta in triggering $\mathrm{Ca}^{2+}$ oscillations during fertilization. Biol Reprod 2005; 72: 992-996. [Medline] [CrossRef]

34. Yazawa H, Yanagida K, Katayose H, Hayashi S, Sato A. Comparison of oocyte activation and $\mathrm{Ca}^{2+}$ oscillation-inducing abilities of round/elongated spermatids of mouse, hamster, rat, rabbit and human assessed by mouse oocyte activation assay. Hum Reprod 2000; 15: 2582-2590. [Medline] [CrossRef]

35. Tachibana M, Terada Y, Ogonuki N, Ugajin T, Ogura A, Murakami T, Yaegash N, Okamura K. Functional assessment of centrosomes of spermatozoa and spermatids microinjected into rabbit oocytes. Mol Reprod Dev 2009; 76: 270-277. [Medline] [CrossRef]

36. Ogonuki N, Mori M, Shinmen A, Inoue K, Mochida K, Ohta A, Ogura A. The effect on intracytoplasmic sperm injection outcome of genotype, male germ cell stage and freeze-thawing in mice. PLoS One 2010; 5: e11062. [Medline] [CrossRef] 